\title{
Modulation of crude glycerol fermentation by Clostridium pasteurianum DSM 525 towards the production of butanol
}

\author{
R. Gallardo ${ }^{1,2}$, M. Alves ${ }^{2}$, L.R. Rodrigues* \\ CEB - Centre of Biological Engineering, University of Minho, 4710-057 Braga, Portugal
}

\section{A R T I C L E I N F O}

Article history:

Received 25 November 2013

Received in revised form

17 September 2014

Accepted 23 October 2014

Available online 13 November 2014

Keywords:

Butanol

Clostridium pasteurianum

Crude glycerol

Butyrate

1,3-Propanediol

\begin{abstract}
A B S T R A C T
High production yields and productivities are requisites for the development of an industrial butanol production process based on biodiesel-derived crude glycerol. However, impurities present in this substrate and/or the concentration of glycerol itself can affect the microbial metabolism. In this work, the effect of crude glycerol concentration on the production of butanol and 1,3-propanediol (1,3-PDO) by Clostridium pasteurianum DSM 525 is studied. Also, the effect of acetate and butyrate supplementation to the culture medium and the culture medium composition are evaluated. The results showed a marked effect of crude glycerol concentration on the product yield. The competitive nature of butanol and 1,3-PDO pathways has been evident, and a shift to the butanol pathway once using higher substrate concentrations (up to $35 \mathrm{~g} \mathrm{l}^{-1}$ ) was clearly observed. Butyrate supplementation to the culture medium resulted in a $45 \%$ higher butanol titre, a lower production of 1,3-PDO and it decreased the fermentation time. Acetate supplementation also increased the butanol titre but the fermentation was longer. Even though glycerol consumption could not be increased over $32 \mathrm{~g} \mathrm{l}^{-1}$, when the concentrations of $\mathrm{NH}_{4} \mathrm{Cl}$ and $\mathrm{FeCl}_{2}$ were simultaneously increased, the results obtained were similar to those observed when butyrate was supplemented to the culture medium; a 35\% higher butanol yield at the expense of 1,3-PDO and a shorter fermentation. The results herein gathered suggest that there are other factors besides butanol inhibition and nutrient limitation that affect the glycerol consumption.
\end{abstract}

(c) 2014 Elsevier Ltd. All rights reserved.

\section{Introduction}

Glycerol is an attractive substrate for anaerobic fermentation that has interesting advantages over simple sugars such as glucose. From the technical point of view, the highly reduced nature of this compound results in twice the amount of reducing equivalents when it is converted to glycolytic intermediates such as pyruvate, which leads to higher yields of reduced compounds such as butanol [1]. On the other hand, glycerol is a by-product in the production of biodiesel and ethanol, representing approximately $10 \%$ and $6 \%(\mathrm{w} / \mathrm{w})$ of the

\footnotetext{
* Corresponding author. Tel.: +351 253 604401; fax: +351 253604429 .

E-mail address: 1rmr@deb.uminho.pt (L.R. Rodrigues).

${ }^{1}$ Current address: Escuela de Ingeniería Bioquímica, Pontificia Universidad Católica de Valparaíso, Valparaíso, Chile.

2 Tel.: +351 253 604401; fax: +351 253604429 .
} 
production, respectively [2]. In this context, the rapid expansion that the biodiesel industry has experienced in the last decades has led to a surplus of crude glycerol in the market, thus a decrease in its price [3], making it an economically competitive substrate. As an example, the current spot price of crude glycerol is $\$ 0.20$ per kilogram in the US (FOB Midwest) [4]. On the other hand, the price of corn (Central Illinois) is $\$ 0.19$ per kilogram [4]. Therefore, if $1 \mathrm{~kg}$ of corn leads to $0.71 \mathrm{~kg}$ of glucose [5], the price of corn-derived glucose, considering only the raw material, can be estimated in $\$ 0.28$ per kilogram.

The production of butanol and 1,3-PDO from either pure or crude biodiesel-derived glycerol by Clostridium pasteurianum has been reported by several authors [6-15]. However, only few researchers used high concentrations of crude glycerol and their results showed a great variability in terms of product yield, titre and productivity. A source of such variability could be the impurities present in the crude glycerol, which potentially include methanol, ash, free fatty acids and triglycerides. Therefore, extra care has been advised regarding the use of crude glycerol, especially in what concerns the remaining methanol, as well as the sodium or potassium salts since they are known to inhibit cell growth [16]. Taconi et al. [14] reported a decrease in the average yield of butanol and longer fermentation times for C. pasteurianum ATCC 6013 when using crude glycerol instead of pure glycerol. Venkataramanan et al. [15] found that linolenic acid, potentially present as nonreacted free fatty acid in biodiesel-derived crude glycerol, strongly inhibits glycerol utilization by C. pasteurianum ATCC 6013. Khanna et al. [11] used C. pasteurianum immobilized cells and found a pronounced decrease in the butanol production from crude glycerol concentrations higher than $25 \mathrm{~g} \mathrm{l}^{-1}$. On the other hand, glycerol itself at high concentrations rather than the impurities that crude glycerol could contain, seems to influence the C. pasteurianum metabolism [8].

In general, two steps, namely acidogenesis and solventogenesis, characterize solvent production by Clostrdium spp. Although the metabolic regulation systems are not fully elucidated, the metabolic pathways present in solventogenic clostridia are well established (Fig. 1).

Even though the conversion of butyrate to butanol does not occur in the absence of a reduced carbon source, it has been reported that the supplementation of the culture medium with this compound (and also with acetate) enhances and stabilizes solvent production in Clostridium beijerinckii [17-20]. However, the supplementation of butyrate as a strategy to increase butanol production from crude glycerol by C. pasteurianum has not been reported. Heyndrickx et al. [9] showed that externally added acetate has an effect on the product distribution in the fermentation of pure glycerol by C. pasteurianum. Contrarily, Harris et al. [21] reported that the supplementation of acetate or butyrate to the culture medium did not influence $C$. pasteurianum fermentation using glucose as the carbon source.

As Datta and Zeikus [22] pointed, a higher butanol titre obtained at the expense of butyrate must be accompanied by a change in the electron flow towards the production of solvents. This situation can be the result of a higher activity of the enzymes involved in the production of solvents from acetate or butyrate. Indeed, Chen and Blanchek [17] reported a higher CoA transferase activity and higher acetate kinase- and

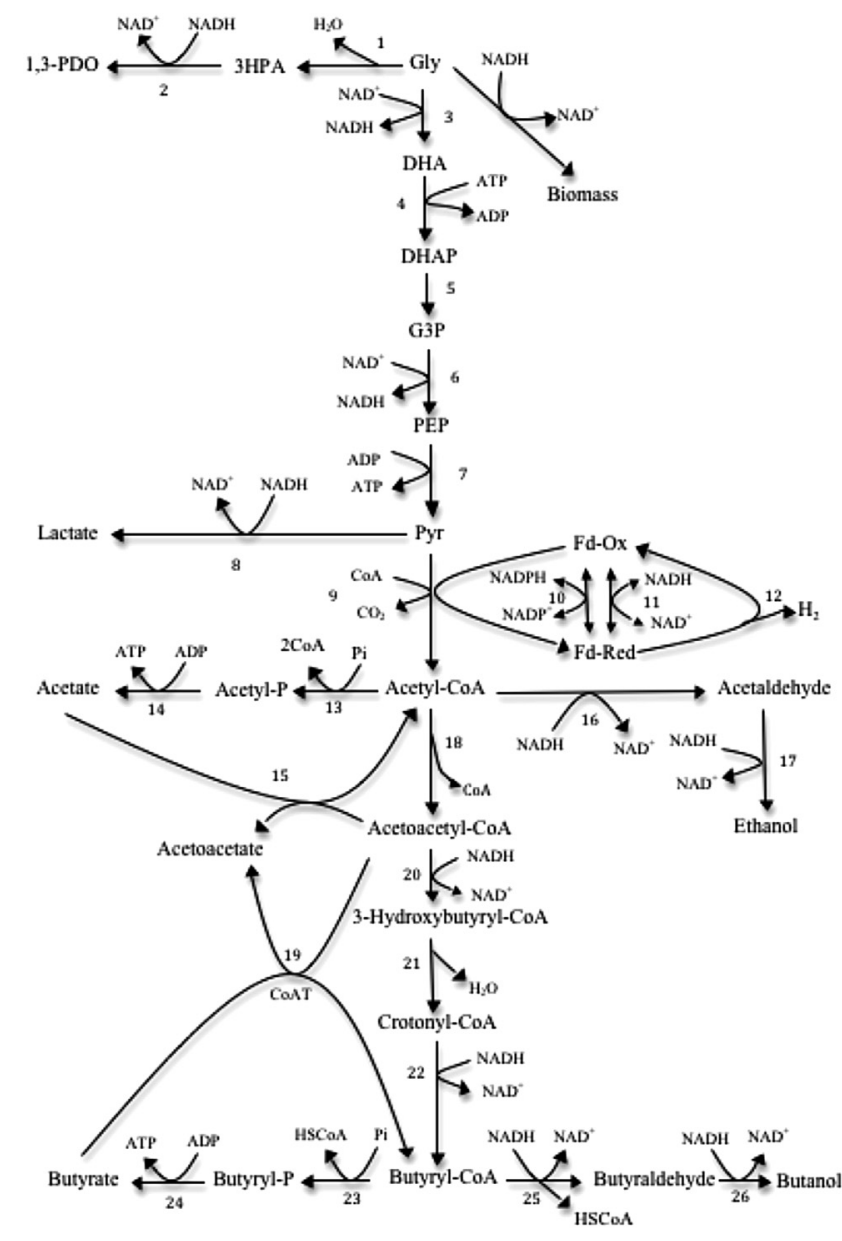

Fig. 1 - Metabolic pathways involved in glycerol degradation by C. pasteurianum. 1: glycerol dehydratase; 2 : 1,3-propanediol oxidoreductase; 3: glycerol-3-phosphate dehydrogenase; 4: dihydroxyacetone kinase; 5: triosephosphate isomerase; 6: glyceraldehyde-3-phosphate dehydrogenase; 7: pyruvate kinase; 8: lactate dehydrogenase; 9: pyruvate-ferredoxin oxidoreductase; 10: NADPH-ferredoxin oxidoreductase; 11: NADHferredoxin oxidoreductase; 12: ferredoxin hydrogenase; 13: phosphate acetyltransferase; 14: acetate kinase; 15:, acetoacetyl-CoA: acetate:CoA transferase; 16: acetaldehyde dehydrogenase; 17: ethanol dehydrogenase; 18: thiolase; 19: acetoacetyl-CoA: butyrate:CoA transferase; 20 : $\beta$ hydroxybutyryl-CoA dehydrogenase; 21: crotonase; 22 : butyryl-CoA dehydrogenase; 23: phosphotransbutyrylase; 24: butyrate kinase; 25: butaraldehyde dehydrogenase; 26: butanol dehydrogenase. Adapted from Malaviya et al. [13].

butyrate kinase specific activity in C. beijerinckii NCIMB 8052 grown in a culture medium supplemented with sodium acetate. Husemann and Papoutsakis [23] showed that the levels of NAD-dependent and NADP-dependent butyraldehyde dehydrogenase, which catalyses the conversion of butyryl-CoA to butyraldehyde (precursor of butanol), were more strongly induced in the presence of $\mathrm{CO}$ and butyric acid.

In this work, the effects of crude glycerol concentration and of the supplementation of the culture medium with acetate and butyrate on the production of butanol and 1,3-PDO by 
C. pasteurianum DSM 525 are studied. Moreover, the composition of the culture medium is evaluated in order to identify possible nutrient limitations and thus to improve the production of butanol.

\section{Material and methods}

\subsection{Strain maintenance and reactivation}

C. pasteurianum DSM 525 was purchased from DSMZ (German collection of microorganisms and cell cultures). Freeze dried cells were reactivated in a semi-defined culture medium containing per litre of distilled water: $40 \mathrm{~g}$ glucose; $1 \mathrm{~g}$ yeast extract; $0.5 \mathrm{~g} \mathrm{KH}_{2} \mathrm{PO}_{4} ; 0.5 \mathrm{~g} \mathrm{~K}_{2} \mathrm{HPO}_{4} ; 0.2 \mathrm{~g} \mathrm{MgSO}_{4} .7 \mathrm{H}_{2} \mathrm{O} ; 0.02 \mathrm{~g}$ $\mathrm{CaCl}_{2} .2 \mathrm{H}_{2} \mathrm{O} ; 3 \mathrm{~g} \mathrm{NH}_{4} \mathrm{Cl} ; 4 \mathrm{~g} \mathrm{NaHCO}$; 0.5 g cysteine-HCl; $1 \mathrm{ml}$ acid micronutrients solution $\left(1.8 \mathrm{~g} \mathrm{l}^{-1} \mathrm{HCl} ; 61.8 \mathrm{mg} \mathrm{l}^{-1} \mathrm{H}_{3} \mathrm{BO}_{3}\right.$; $61.3 \mathrm{mg} \mathrm{l}^{-1} \mathrm{MnCl}_{2} ; 943.5 \mathrm{mg} \mathrm{l}^{-1} \mathrm{FeCl}_{2} ; 64.5 \mathrm{mg} \mathrm{l}^{-1} \mathrm{CoCl}_{2}$; $\left.12.9 \mathrm{mg} \mathrm{l}^{-1} \mathrm{NiCl}_{2} ; 67.7 \mathrm{mg} \mathrm{l}^{-1} \mathrm{ZnCl}_{2}\right)$ and $1 \mathrm{ml}$ alkaline micronutrients solution (0.4 $\mathrm{g} \mathrm{l}^{-1} \mathrm{NaOH} ; 17.3 \mathrm{mg} \mathrm{l}^{-1} \mathrm{Na}_{2} \mathrm{SeO}_{3}$; $29.4 \mathrm{mgl}^{-1} \mathrm{Na}_{2} \mathrm{WO}_{4} ; 20.5 \mathrm{mgl}^{-1} \mathrm{Na}_{2} \mathrm{MoO}_{4}$ ) under a $\mathrm{N}_{2}-\mathrm{CO}_{2}$ gas mixture $(80 \%-20 \%)$ atmosphere. Stock cultures were kept at room temperature and were transferred to fresh medium periodically.

\subsection{Analytical methods}

Acids, glycerol and 1,3-PDO were measured through high performance liquid chromatography (Aminex cationexchange HPX-87H column) equipped with UV and RI detectors. The column was eluted isocratically with $\mathrm{H}_{2} \mathrm{SO}_{4} 0.01 \mathrm{~N}$

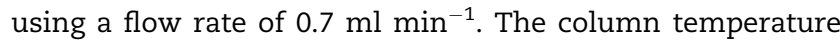
was set at $60{ }^{\circ} \mathrm{C}$. Ethanol and butanol were measured by gas chromatography (TR-WAX capillary column) equipped with a flame ionization detector. A temperature ramp $\left(0.5^{\circ} \mathrm{C} \mathrm{min}-1\right)$ was used for the column and the temperatures of the injector and detector were kept at $200{ }^{\circ} \mathrm{C}$ and $250^{\circ} \mathrm{C}$, respectively.

\subsection{Experimental procedure}

The strain was anaerobically cultured in $500 \mathrm{ml}$ serum bottles using a working volume of $200 \mathrm{ml}$. Ten per cent culture volume was repeatedly transferred to increasing biodieselderived crude glycerol concentrations using the semidefined culture medium described in Section 2.1, in which the glucose was replaced by crude glycerol. Alternatively, the $\mathrm{NaHCO}_{3}-\mathrm{CO}_{2}$ buffer was changed by $\mathrm{CaCO}_{3}$ and the serum bottles were pressurized with $\mathrm{N}_{2}$. The crude glycerol used was kindly provided by a Portuguese biodiesel producer. The composition (w/w) of the crude glycerol was glycerol $(85 \%$ min.), ash (6\% max.), non-glycerol organic matter (2.5\% max.), moisture (8-10\%), and methanol (0.1\% max.). For each crude glycerol concentration, four bottles were prepared. Samples were taken at regular time intervals from three bottles until the end of the fermentation and one bottle was used as inoculum to transfer cells in a vegetative stage (12-24 h). Alternatively, cells were transferred at the end of the fermentation, thus allowing them to sporulate. The crude glycerol concentrations used were 5, 10, 15, 20, 35 and $50 \mathrm{gl}^{-1}$.

The effect of butyrate on the fermentation of crude glycerol by C. pasteurianum DSM 525 was evaluated in culture media containing $5-50 \mathrm{~g} \mathrm{l}^{-1}$ crude glycerol by using sodium butyrate in a concentration of $3.87 \pm 0.42 \mathrm{~g} \mathrm{l}^{-1}$. The supplementation of sodium acetate at the same concentration was also evaluated in culture media containing $50 \mathrm{~g} \mathrm{l}^{-1}$ crude glycerol. The experiments were conducted in parallel with those described above.

In order to obtain preliminary information about possible nutrient limitations and aiming to improve glycerol consumption and butanol production, the effect of different nutrients $\left(\mathrm{NH}_{4} \mathrm{Cl}, \mathrm{CaCO}_{3}, \mathrm{FeCl}_{2}\right.$, microelements, salts, yeast extract, biotin and p-aminobenzoic acid) was evaluated by increasing their concentrations in independent experiments as showed in Table 1 . The experiments were conducted in $160 \mathrm{ml}$ serum bottles containing $60 \mathrm{ml}$ of culture medium (50 $\mathrm{g} \mathrm{l}^{-1}$ crude glycerol). The bottles were inoculated with $10 \%$ of an exponential culture of $C$. pasteurianum and the fermentation products were measured as described in Section 2.2. The results were statistically analysed using an F-test TwoSample for Variances and subsequently a t-test assuming equal or unequal variances. In all experiments, the initial culture $\mathrm{pH}$ was adjusted to $6.8 \pm 0.2$ and cells were incubated at $37^{\circ} \mathrm{C}$ without agitation.

Table 1 - Nutrient combinations used to identify possible nutrient limitations in cultures containing an initial glycerol concentration of $50 \mathrm{~g} \mathrm{l}^{-1}$.

\begin{tabular}{|c|c|c|c|c|c|c|c|c|}
\hline Experiment & $\begin{array}{l}\mathrm{NH}_{4} \mathrm{Cl} \\
\left(\mathrm{g} \mathrm{l}^{-1}\right)\end{array}$ & $\begin{array}{l}\mathrm{CaCO}_{3} \\
\left(\mathrm{~g} \mathrm{l}^{-1}\right)\end{array}$ & $\begin{array}{l}\text { Yeast extract } \\
\qquad\left(\mathrm{g} \mathrm{l}^{-1}\right)\end{array}$ & $\begin{array}{c}\text { Biotin } \\
\left(\mathrm{mg} \mathrm{l}^{-1}\right)\end{array}$ & $\begin{array}{c}\text { p-aminobenzoic acid } \\
\left(\mathrm{mg} \mathrm{l}^{-1}\right)\end{array}$ & $\begin{array}{c}\mathrm{FeCl}_{2} \\
\left(\mathrm{mg} \mathrm{l}^{-1}\right)\end{array}$ & Salts $^{a}$ & Microelements $^{b}$ \\
\hline 1 & 3 & 3 & 1 & 0 & 0 & 1 & x 1 & x 1 \\
\hline 2 & 5 & 3 & 1 & 0 & 0 & 1 & x 1 & x 1 \\
\hline 3 & 5 & 3 & 1 & 0 & 0 & 11 & x 1 & x 1 \\
\hline 4 & 5 & 3 & 1 & 0 & 0 & 11 & x 1 & x 3 \\
\hline 5 & 5 & 3 & 1 & 0.01 & 1 & 11 & $\mathrm{x} 1$ & x 3 \\
\hline 6 & 5 & 5 & 2 & 0 & 0 & 11 & x 1 & x 3 \\
\hline 7 & 5 & 5 & 1 & 0 & 0 & 11 & x 1.5 & x 3 \\
\hline 8 & 5 & 10 & 1 & 0 & 0 & 11 & $\mathrm{x} 1$ & x 3 \\
\hline 9 & 5 & 1.5 & 1 & 0 & 0 & 11 & $\mathrm{x} 1$ & x 3 \\
\hline
\end{tabular}

a,b The notation $\mathrm{x} 1, \mathrm{x} 1.5, \mathrm{x} 3$ indicates that the concentration of the corresponding nutrients in the culture medium was increased by a factor of

$1,1.5$ and 3 , respectively.

a Corresponds to $\mathrm{KH}_{2} \mathrm{PO}_{4}, \mathrm{~K}_{2} \mathrm{HPO}_{4}$, and $\mathrm{MgSO}_{4} .7 \mathrm{H}_{2} \mathrm{O}$.

b Corresponds to trace elements solution 6 and solution 7 . 
Table 2 - Batch fermentation of crude glycerol by C. pasteurianum DSM 525 at $37{ }^{\circ} \mathrm{C}$ without pH control. Results represent the average of three independent assays \pm S.D.

\begin{tabular}{|c|c|c|c|c|c|c|c|c|c|}
\hline $\begin{array}{l}\text { Initial } \\
\text { glycerol } \\
\left(\mathrm{g} \mathrm{l}^{-1}\right)\end{array}$ & $\begin{array}{c}\text { Glycerol } \\
\text { consumption } \\
\left(\mathrm{g} \mathrm{l}^{-1}\right)\end{array}$ & $\begin{array}{c}\text { Final } \\
\text { butanol } \\
\left(\mathrm{g} \mathrm{l}^{-1}\right)\end{array}$ & $\begin{array}{l}\text { Qbutanol } \\
\left(\mathrm{g} \mathrm{l}^{-1} \mathrm{~h}^{-1}\right)\end{array}$ & $\begin{array}{c}\text { Final } \\
\text { ethanol } \\
\left(\mathrm{g} \mathrm{l}^{-1}\right)\end{array}$ & $\begin{array}{l}\text { Final 1,3- } \\
\text { PDO }\left(\mathrm{g} \mathrm{l}^{-1}\right)\end{array}$ & $\begin{array}{l}\text { Q1,3-PDO } \\
\left(\mathrm{g} \mathrm{l}^{-1} \mathrm{~h}^{-1}\right)\end{array}$ & $\begin{array}{c}\text { Final acetic } \\
\text { acid }\left(\mathrm{g} \mathrm{l}^{-1}\right)\end{array}$ & $\begin{array}{l}\text { Final butyric } \\
\text { acid }\left(\mathrm{g} \mathrm{l}^{-1}\right)\end{array}$ & $\begin{array}{l}\text { Final lactic } \\
\text { acid }\left(\mathrm{g} \mathrm{l}^{-1}\right)\end{array}$ \\
\hline $4.72^{\mathrm{a}}$ & 4.71 & 0.17 & 0.003 & 0.06 & 1.80 & 0.032 & 0.74 & 0.87 & 0.33 \\
\hline $8.87 \pm 0.08$ & $8.83 \pm 0.08$ & $0.77 \pm 0.19$ & $0.016 \pm 0.004$ & $0.18 \pm 0.01$ & $2.71 \pm 0.21$ & $0.051 \pm 0.003$ & $0.99 \pm 0.05$ & $0.94 \pm 0.05$ & $0.51 \pm 0.07$ \\
\hline $16.69 \pm 1.44$ & $16.69 \pm 1.44$ & $2.21 \pm 0.11$ & $0.039 \pm 0.001$ & $0.34 \pm 0.00$ & $4.80 \pm 0.16$ & $0.051 \pm 0.005$ & $1.52 \pm 0.12$ & $1.63 \pm 0.05$ & $0.61 \pm 0.05$ \\
\hline $19.33 \pm 0.06$ & $19.07 \pm 0.17$ & $2.42 \pm 0.10$ & $0.021 \pm 0.002$ & $0.26 \pm 0.00$ & $5.89 \pm 0.23$ & $0.053 \pm 0.003$ & $1.66 \pm 0.10$ & $1.83 \pm 0.17$ & $0.84 \pm 0.10$ \\
\hline $32.80 \pm 1.02$ & $31.30 \pm 1.18$ & $6.71 \pm 0.43$ & $0.050 \pm 0.008$ & $0.59 \pm 0.05$ & $6.86 \pm 0.51$ & $0.060 \pm 0.002$ & $0.83 \pm 0.08$ & $0.43 \pm 0.08$ & $0.73 \pm 0.18$ \\
\hline $44.13 \pm 0.69$ & $29.68 \pm 1.43$ & $6.73 \pm 0.39$ & $0.041 \pm 0.002$ & $0.68 \pm 0.04$ & $6.26 \pm 0.27$ & $0.077 \pm 0.010$ & $0.69 \pm 0.03$ & $0.21 \pm 0.03$ & $1.24 \pm 0.04$ \\
\hline
\end{tabular}

\section{Results and discussion}

Fast growth and almost complete substrate consumption was observed in experiments using up to $20 \mathrm{~g} \mathrm{l}^{-1}$ initial crude glycerol concentration. Similar to previous reports about glycerol fermentation by $C$. pasteurianum $[7,8,13]$, the main fermentation products found were acetic acid, butyric acid, lactic acid, butanol and 1,3- PDO. However, even though butanol and ethanol were produced in experiments using $5 \mathrm{gl}^{-1}$ crude glycerol and in one out of three bottles containing $10 \mathrm{~g} \mathrm{l}^{-1}$ crude glycerol, the solvent producing capacity of the cells was lost and only traces of alcohols were detected in the subsequent transfers. Higher production of acids, including isobutyric acid (not observed in normal cultures) and 1,3-PDO was detected when solvents were absent.

One of the main problems in the production of solvents using Clostridium spp., besides the toxicity of the end product butanol, is the so-called strain degeneration. This situation is basically the loss of the solvent capacity of the cells during repeated subculture in batch and continuous culture and it has been reported in Clostridium acetobutylicum and C. beijerinckii [24-26]. However, this issue has been rather neglected in C. pasteurianum.

The standard practice to avoid stain degeneration of Clostridium spp. has been to maintain cells as spores, which can be, heat activated and germinated when an inoculum is required [25]. On the other hand, it has been reported that $C$. acetobutylicum can be sub-cultured in a medium containing an excess of $\mathrm{CaCO}_{3}$ for more than 200 days without losing its ability to produce solvents, and also that it is possible to restore the initial solvent yields by increasing the volume of the inoculum used [27]. Nevertheless, Taconi and collaborators [14] reported the loss of solvent capacity in C. pasteurianum ATCC 61013 although they used an excess of $\mathrm{CaCO}_{3}$ and even when they centrifuged and transferred all the cells. Therefore, these strategies seem to be useless for C. pasteurianum. The addition of acetate $[17,18]$ and butyrate $[20,28]$ to the culture medium has also shown to prevent strain degeneration and to enhance solvent production.

In an attempt to restore the solvent production, and based on the information reported in literature, those cells cultured in $20 \mathrm{~g} \mathrm{l}^{-1}$ crude glycerol that did not produce solvents were transferred to culture media with the following differences: (a) $3 \mathrm{~g} \mathrm{l}^{-1}$ of $\mathrm{CaCO}_{3}$ and $\mathrm{N}_{2}$ in the headspace instead of $\mathrm{CO}_{2}-\mathrm{NaHCO}_{3}$ (change in buffer system)

(b) Twice the volume of inoculum (20\%)

(c) $4 \mathrm{~g} \mathrm{l}^{-1}$ of sodium butyrate in the culture medium

Despite the new conditions used, the product profile was the same and the solvent production capacity of the cells could not be restored. This situation suggests that at least one of the enzymes involved in the conversion of butyrate to butanol (Fig. 1) was not present or was inactive.

New experiments were started from a stock culture using $\mathrm{CaCO}_{3}$ as buffer agent instead of $\mathrm{NaHCO}_{3}-\mathrm{CO}_{2}$ and cells were transferred at the end of the fermentation, thus allowing them to sporulate. Even though in this new experimental set up strain degeneration was observed in experiments using 5 and $10 \mathrm{~g} \mathrm{l}^{-1}$ of crude glycerol, it was still possible to select and transfer degeneration-resistant cells, thus guaranteeing that this situation was overcome through the rest of the work.

Cells were serially transferred to culture media containing $5,10,15,20,35$, and $50 \mathrm{gl}^{-1}$ of crude glycerol (Table 2). As in the first experiments, the main products found were butanol and 1,3-PDO besides minor quantities of ethanol and acids (acetic, n-butyric, lactic). Moreover, the competitive nature of butanol and 1,3-PDO pathways was evident, and a shift to the butanol pathway for higher crude glycerol concentrations (up to $35 \mathrm{~g} \mathrm{l}^{-1}$ ) was clearly observed (Fig. 2), which indeed is a positive fact for the industrial production of butanol. Further increases in crude glycerol concentration did not promote any improvement on the production of butanol.

The product profile herein obtained differs from the results reported by Biebl [7] and Dabrock et al. [8] who studied the influence of glycerol (pure) concentration using C. pasteurianum DSM 525. Biebl [7] found that the butanol/1,3 -PDO ratio varied considerably but without noticeable relation to the glycerol concentration up to $114.6 \mathrm{~g} \mathrm{l}^{-1}$. On the other hand, Dabrock et al. [8] found that up to $8 \%(\mathrm{w} / \mathrm{v})$ glycerol, the ratio ethanol/butanol/1,3-PDO did not change and that higher glycerol concentrations favoured the production of 1,3-PDO at the expense of ethanol.

The strain was able to consume a maximum of $31.30 \pm 1.18 \mathrm{~g} \mathrm{l}^{-1}$ of glycerol, which resulted in $6.71 \pm 0.43 \mathrm{~g} \mathrm{l}^{-1}$ of butanol and $6.86 \pm 0.51 \mathrm{~g} \mathrm{l}^{-1}$ of 1,3-PDO. Figs. 3 and 4 illustrate the glycerol consumption and butanol, ethanol and 1,3PDO production along the time for cultures containing 35 


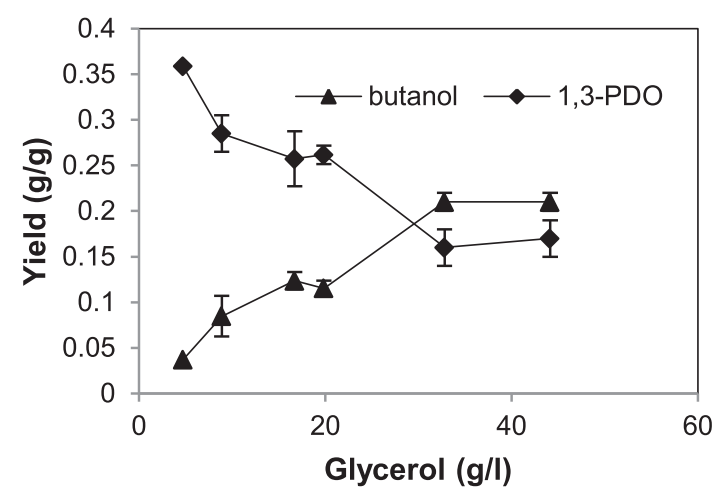

Fig. 2 - Butanol and 1,3-PDO yield versus glycerol concentration in batch fermentation of crude glycerol by $C$. pasteurianum DSM 525 at $37^{\circ} \mathrm{C}$ without pH control. Results represent the average of three independent experiments \pm S.D.

and $50 \mathrm{~g} \mathrm{l}^{-1}$ initial crude glycerol concentration, respectively. In both cultures, glycerol was rapidly consumed during the first $50 \mathrm{~h}$, after which it was found a marked decrease in the consumption rate, probably due to butanol accumulation in the culture medium. As observed in all the experiments conducted, the amount of ethanol produced by the cells was residual in comparison with butanol, which is in agreement with the results presented by Biebl [7] and Malaviya et al. [13], although different from the ones presented by Dabrock et al. [8]. Interestingly, butanol was produced from the beginning of the fermentation and along with acids (data not shown), which differs from the classical biphasic ABE fermentation. Moreover, a clear association between butanol production and cell growth was reported by Biebl [7] using C. pasteurianum DSM 525 and glycerol at pH 6.0.

The fact that the strain was not able to consume more than $32 \mathrm{~g} \mathrm{l}^{-1}$ of glycerol is likely to be related with nutrient limitation, product inhibition, the $\mathrm{pH}$ of the culture medium and/or other physiological parameters. However, the accumulation of some toxic compound through the repeated sub-culturing cannot be discarded.

The glycerol consumption obtained in this work is slightly higher than the maximum glycerol consumption reported by

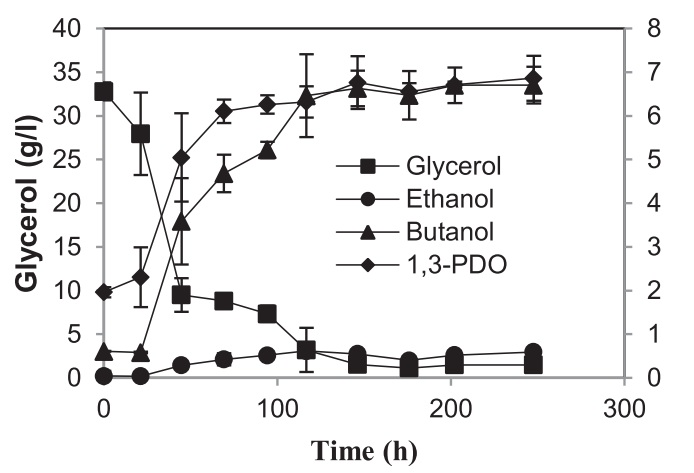

Fig. 3 - Batch fermentation of $35 \mathrm{~g} \mathrm{l}^{-1}$ crude glycerol by $\mathrm{C}$. pasteurianum DSM 525 at $37^{\circ} \mathrm{C}$ without pH control. Results represent the average of three independent experiments \pm S.D.

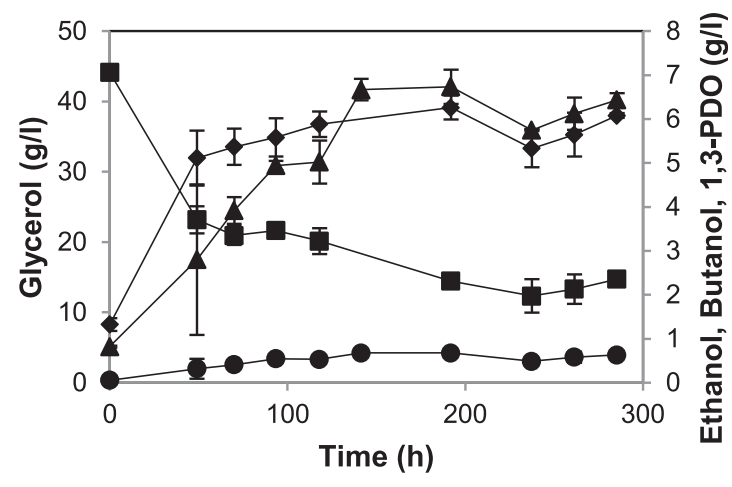

$\longrightarrow$ Gly $\longleftarrow$ Butanol $\longrightarrow$ Ethanol $\multimap$ 1,3-PDO

Fig. 4 - Batch fermentation of $50 \mathrm{~g} \mathrm{l}^{-1}$ crude glycerol by $\mathrm{C}$. pasteurianum DSM 525 at $37{ }^{\circ} \mathrm{C}$ without pH control. Results represent the average of three independent experiments \pm S.D.

Dabrock et al. [8] (27.6 $\left.\mathrm{g} \mathrm{l}^{-1}\right)$, but lower than the value reported by Biebl [7] (63.6 $\mathrm{g} \mathrm{l}^{-1}$ ). Regarding the production of butanol and 1,3-PDO, Dabrock et al. [8] showed an increase in butanol production from 2 to $8 \%(\mathrm{w} / \mathrm{v})$ glycerol in the culture medium, after which, its concentration remained more or less constant up to $17 \%(\mathrm{v} / \mathrm{w})$. At this glycerol concentration the authors reported $3.33 \mathrm{~g} \mathrm{l}^{-1}$ of butanol and $10.04 \mathrm{~g} \mathrm{l}^{-1}$ of 1,3-PDO. The fermentations herein conducted resulted in a higher titre and yield of butanol, which is probably related with the composition of the culture medium used in the fermentation. In fact, Dabrock et al. [8] used a semi-defined culture medium containing an unusually high concentration of biotin $\left(0.24 \mathrm{mgl}^{-1}\right)$, which has been reported as a required growth factor for the production of 1,3-propanediol by Clostridium butyricum [29]. Also, the authors used a low concentration of nitrogen source $\left(0.66 \mathrm{~g} \mathrm{l}^{-1}\right)$, which has been reported to favour the production of 1,3-PDO by C. pasteurianum DSM 525 [30].

On the other hand, Biebl [7] reported a maximum glycerol consumption of $63.6 \mathrm{~g} \mathrm{l}^{-1}$ using an initial concentration of $114.6 \mathrm{gl}^{-1}$. The authors also reported the production of $14 \mathrm{gl}^{-1}$ of butanol, which is surprisingly high for the wild-type strain in comparison with the results herein obtained and other reports from literature. The main difference between the experiments conducted by Biebl [7] and the ones of the present work is the use of a $\mathrm{pH}$-controlled reactor.

The $\mathrm{pH}$ and operational parameters have been recognized as important factors in the fermentation of glycerol by $C$. pasteurianum. Dabrock et al. [8] showed that in continuous culture at $\mathrm{pH}$ values below 5.5 the growth of $\mathrm{C}$. pasteurianum and the substrate turnover started to decrease, and that at $\mathrm{pH}$ values below 4.8 the steady-state conditions could not be obtained anymore. Similarly, Biebl [7] studied the effect of $\mathrm{pH}$ on glycerol (pure) fermentation by C. pasteurianum DSM 525 in a $\mathrm{pH}$-controlled reactor over a $\mathrm{pH}$ range of 4.5-7.5 and found that at pH 4.5 only part of the substrate was used after a prolonged fermentation time. The author reported that the optimal pH for butanol production was 6.0. Even though a low $\mathrm{pH}$ could limit the consumption of glycerol by stopping the fermentation, it should be mentioned that the lowest $\mathrm{pH}$ value 


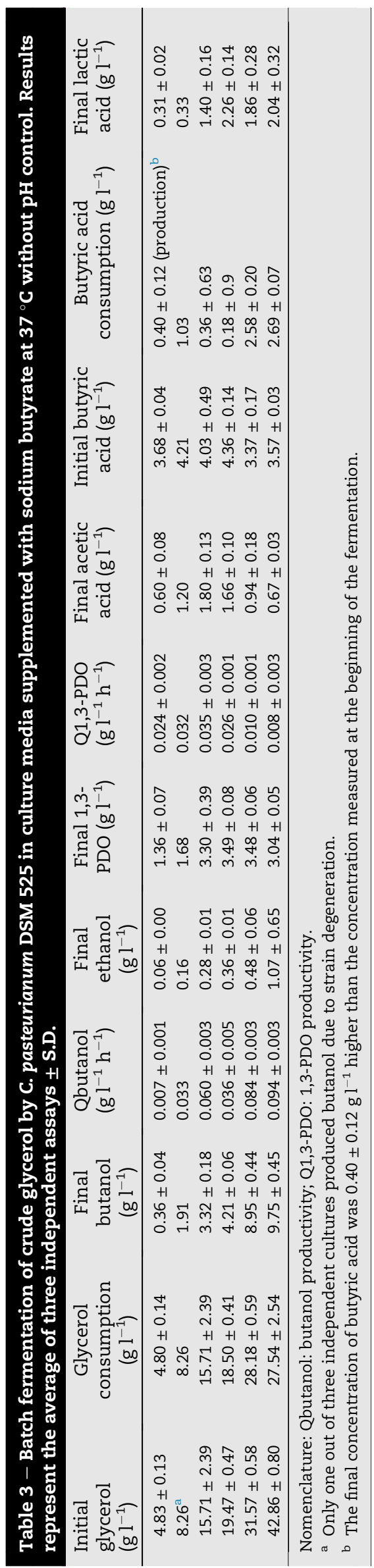

measured in the experiments conducted in the present work was 4.8, however usual values were over 5.0.

Malaviya et al. [13] developed a hyper-producing mutant of C. pasteurianum by random chemical mutagenesis. In preliminary experiments, the authors compared the mutant strain with the parent strain in flask cultures using $80 \mathrm{~g} \mathrm{l}^{-1}$ of glycerol and reported an average butanol production of $10.8 \mathrm{~g} \mathrm{l}^{-1}$ and $7.7 \mathrm{~g} \mathrm{l}^{-1}$, respectively, which is similar to the results herein obtained. No information on the glycerol consumption was provided in that report. Similarly to Biebl [7] and Dabrock et al. [8], the authors reported that when the same experiment was conducted in a $\mathrm{pH}$-controlled reactor ( $\mathrm{pH}$ above 4.5 or 4.8 ), the butanol concentrations increased to $10 \mathrm{~g} \mathrm{l}^{-1}$ and $13.7 \mathrm{~g} \mathrm{l}^{-1}$ for the parent and mutant strain, respectively. The authors further studied several parameters using the mutant strain, such as initial cell density, inoculum age and initial $\mathrm{pH}$. In these experiments, conducted in serum bottles, they reported a maximum butanol production of $9.4 \pm 0.02 \mathrm{gl}^{-1}$. Again, when the mutant strain was grown in a $\mathrm{pH}$-controlled reactor, the butanol production increased to $14.2 \pm 0.12$ and $15.5 \pm 0.09$, respectively. It is worth to note that this is almost the same value found by Biebl [7] for the wildtype C. pasteurianum DSM 525.

Regarding a possible negative effect of the impurities present in crude glycerol on cell metabolism, it is important to stress that it is unlikely that methanol concentrations in the culture medium are high enough to exert a severe inhibition of the cell metabolism. As an example, it was reported that $40 \mathrm{gl}^{-1}$ methanol caused $61 \%$ inhibition in the cell growth of $C$. acetobutylicum [31]. The maximum concentration of methanol in the crude glycerol used in this work was $0.1 \%$ (w/w), which could result in a maximum concentration of $0.5 \mathrm{~g} \mathrm{l}^{-1}$ of this compound in a culture medium containing $50 \mathrm{~g} \mathrm{l}^{-1}$ of crude glycerol. Moreover, Venkataramanan et al. [15] studied the impact of impurities in biodiesel-derived crude glycerol on the fermentation by C. pasteurianum ATCC 6013 and found that salts and methanol had no negative effects on the growth and metabolism of the microorganism. However, the possible presence of linolenic acid in the crude glycerol could affect glycerol consumption, especially at high concentrations.

Overall, the supplementation of the culture medium with sodium butyrate resulted in higher butanol titres (Table 3). Using $50 \mathrm{~g} \mathrm{l}^{-1}$ of crude glycerol, the final butanol concentration was $9.75 \pm 0.45 \mathrm{~g} \mathrm{l}^{-1}$ versus $6.73 \pm 0.39 \mathrm{~g} \mathrm{l}^{-1}$ obtained in the control. The concentration of 1,3-PDO reached $3.04 \pm 0.05 \mathrm{gl}^{-1}$ versus $6.26 \pm 0.67 \mathrm{~g} \mathrm{l}^{-1}$ obtained in the control. The glycerol consumption was not notoriously affected by the butyrate supplementation, being in this case $27.54 \pm 2.54 \mathrm{gl}^{-1}$. The fact that the supplementation of the culture medium with sodium butyrate resulted in higher butanol titres demonstrates that the glycerol consumption in the control cultures was not limited by butanol inhibition.

It is important to stress that a higher butanol titre obtained as a result of butyrate addition does not necessarily means a higher butanol on glycerol yield since butyrate can be directly converted into butanol via butyryl-CoA - butyraldehyde butanol and/or the reverse phosphotransbutyrylase - butyrate kinase metabolic pathway as it has been demonstrated in $C$. acetobutylicum [32,33] and suggested in C. beijerinckii [34]. However, butyrate was significantly consumed only in the 
cultures with 35 and $50 \mathrm{~g} \mathrm{l}^{-1}$ of initial crude glycerol concentrations.

The culture with $50 \mathrm{~g} \mathrm{l}^{-1}$ initial crude glycerol concentration in which sodium butyrate was supplemented resulted in the consumption of $2.69 \pm 0.07 \mathrm{~g} \mathrm{l}^{-1}$ of butyric acid. On the contrary, the control culture produced $0.21 \pm 0.03 \mathrm{~g} \mathrm{l}^{-1}$ of this compound. If we consider an equimolar conversion of butyrate to butanol, and that all external butyrate was converted to butanol [35], the amount generated by this way would be $2.3 \mathrm{gl}^{-1}$, which is almost the difference observed between the butanol production in the culture where external butyrate was added and the control $\left(3.02 \pm 0.60 \mathrm{~g} \mathrm{l}^{-1}\right)$.

Another effect of the butyrate supplementation to the culture medium was a decrease in the fermentation time, which combined with the higher titre obtained, resulted in more than twice the volumetric butanol productivity $\left(0.094 \pm 0.003 \mathrm{~g} \mathrm{l}^{-1} \mathrm{~h}^{-1}\right.$ vs. $\left.0.041 \pm 0.002 \mathrm{~g} \mathrm{l}^{-1} \mathrm{~h}^{-1}\right)$ in the fermentation with $50 \mathrm{gl}^{-1}$ initial crude glycerol concentration. Consumption of butyric acid started after a marked $\mathrm{pH}$ drop from $6.9 \pm 0.1$, to $5.5 \pm 0.1$ and accompanied the production of butanol, (Fig. 5). After butyric acid was consumed, butanol reached its maximum concentration and the $\mathrm{pH}$ increased to a maximum of $5.9 \pm 0.2$.

Cultures supplemented with sodium butyrate showed the same yield behaviour as those without external butyrate addition, i.e. an increase in the butanol yield at the expense of 1,3-PDO as the crude glycerol concentration was increased. Fig. 6 illustrates the 1,3-PDO and butanol yield assuming that butanol was formed only by the glycerol consumed.

Even though the results obtained clearly show that it is possible to increase the butanol volumetric productivity in the fermentation of crude glycerol by C. pasteurianum by supplementing the culture medium with butyrate, it is worth mentioning that economic factors could hamper the use of this compound as co-substrate. However, innovative solutions have been proposed in the literature. Especially interesting are those involving two-stage fermentations in which the first stage is dedicated to the production of butyric acid

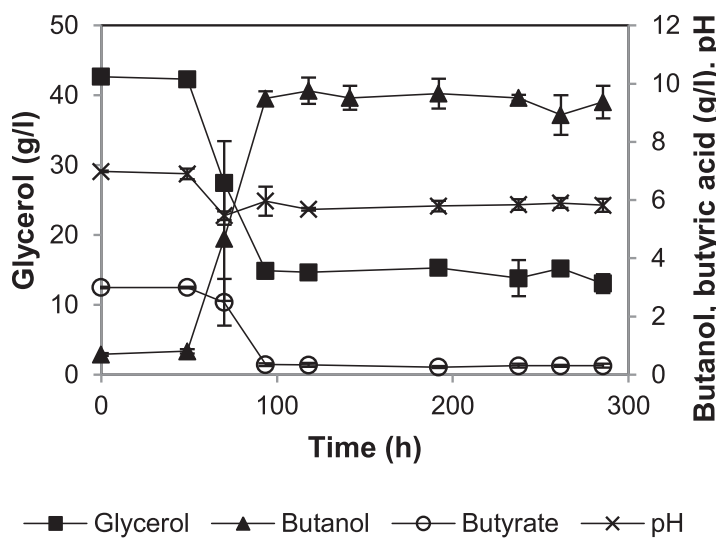

Fig. 5 - Butyric acid consumption and pH behaviour during the butanol production from glycerol by C. pasteurianum DSM 525 in batch culture at $37{ }^{\circ} \mathrm{C}$ without pH control. In this experiment $50 \mathrm{~g} \mathrm{l}^{-1}$ of crude glycerol and $36 \mathrm{mM}$ of sodium butyrate were used. Results represent the average of three independent assays \pm S.D.

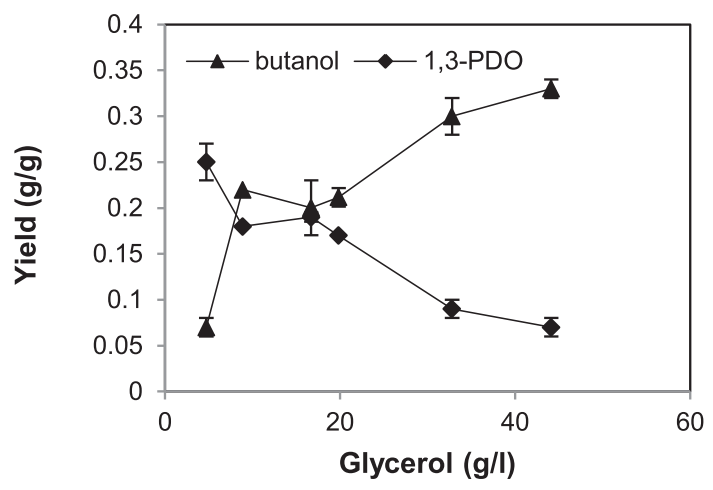

Fig. 6 - Butanol and 1,3-PDO yields versus glycerol concentration in a batch fermentation using crude glycerol and sodium butyrate. Experiments were conducted at $37^{\circ} \mathrm{C}$ without $\mathrm{pH}$ control Results represent the average of three independent assays \pm S.D.

either using the same [36] or a different strain [37]. Moreover, the use of waste-derived feedstock for this purpose could improve the process economy, although each substrate should be individually evaluated [38]. On the other hand, butyric acid is usually present in various waste streams from agricultural and industrial processes [34].

The supplementation of sodium acetate to culture media with $50 \mathrm{~g} \mathrm{l}^{-1}$ crude glycerol resulted also in a higher butanol production by $C$. pasteurianum. However, the butanol titre obtained was lower than in those cultures in which sodium butyrate was used $\left(8.95 \pm 0.27 \mathrm{~g} \mathrm{l}^{-1}\right.$ versus $\left.9.75 \pm 0.45 \mathrm{~g} \mathrm{l}^{-1}\right)$. Furthermore, the fermentation was longer than the control cultures and the ones in which sodium butyrate was supplemented. Similar to those cultures in which sodium butyrate was used, glycerol consumption was not significantly affected $\left(33.5 \pm 1.95 \mathrm{~g} \mathrm{l}^{-1}\right)$.

Even though more butanol could be formed from butyrate and therefore the yield of butanol reported is "apparent", an interesting fact is the lower yield of 1,3-PDO that was obtained. This situation shows that the supplementation of the culture medium with sodium butyrate affects the electron flow in the fermentation of crude glycerol by C. pasteurianum. The reducing equivalents formed during glycolysis are redirected to the production of butanol instead of 1,3-PDO (and probably hydrogen). This is in agreement with the findings reported in the literature and supports the hypothesis that butyrate supplementation is responsible for a higher activity of the enzymes involved in the production of butanol from this compound.

The results herein gathered, demonstrated that it is possible to obtain $9.75 \pm 0.45 \mathrm{~g} \mathrm{l}^{-1}$ of butanol, thus suggesting that cells did not consume more glycerol as a result of nutrient limitation and not due to butanol inhibition. Therefore, the evaluation of the culture medium composition was considered necessary at this point. The results of the experiments described in Table 1 (Section 2.3) are shown in Table 4.

Although it was not possible to increase the glycerol consumption by adjusting the culture medium composition, the experiments conducted resulted in significant differences in the product distribution. In particular, an increase in the concentration of $\mathrm{NH}_{4} \mathrm{Cl}$ from 3 to $5 \mathrm{~g} \mathrm{l}^{-1}$ (Experiment 2) led to 
Table 4 - Evaluation of effect of the culture medium composition on the final yields of butanol and 1,3-PDo. The experiments were conducted in batch at $37{ }^{\circ} \mathrm{C}$ without $\mathrm{pH}$ control and using $50 \mathrm{~g} \mathrm{l}^{-1} \mathrm{crude}_{\text {glycerol. }}$

\begin{tabular}{lcccccccc} 
Experiment $^{\mathrm{a}}$ & $\begin{array}{c}\text { Glycerol } \\
\text { initial }\left(\mathrm{g} \mathrm{l}^{-1}\right)\end{array}$ & $\begin{array}{c}\text { Glycerol } \\
\text { consumption } \\
\left(\mathrm{g} \mathrm{l}^{-1}\right)\end{array}$ & $\begin{array}{c}\text { Butanol final } \\
\left(\mathrm{g} \mathrm{l}^{-1}\right)\end{array}$ & $\begin{array}{c}1,3-\mathrm{PDO} \\
\text { final }\left(\mathrm{g} \mathrm{l}^{-1}\right)\end{array}$ & $\begin{array}{c}\mathrm{Y} \text { Butanol } \\
\left(\mathrm{g} \mathrm{g}^{-1}\right)\end{array}$ & $\begin{array}{c}\text { Qbutanol } \\
\left(\mathrm{g} \mathrm{l}^{-1} \mathrm{~h}^{-1}\right)\end{array}$ & $\begin{array}{c}\mathrm{Y} 1,3-P D O \\
\left(\mathrm{~g} \mathrm{~g}^{-1}\right)\end{array}$ & $\begin{array}{c}\text { Q1,3-PDO } \\
\left(\mathrm{g} \mathrm{l}^{-1} \mathrm{~h}^{-1}\right)\end{array}$ \\
\hline 1 (control) & $44.13 \pm 0.69$ & $29.68 \pm 1.43$ & $6.73 \pm 0.39$ & $6.26 \pm 0.27$ & $0.20 \pm 0.01$ & $0.041 \pm 0.002$ & $0.17 \pm 0.01$ & $0.077 \pm 0.010$ \\
2 & $49.03 \pm 0.86$ & $31.97 \pm 0.69$ & $8.28 \pm 0.39$ & $3.18 \pm 0.26$ & $0.23 \pm 0.01$ & $0.069 \pm 0.004$ & $0.08 \pm 0.01$ & $0.026 \pm 0.007$ \\
3 & $46.94 \pm 0.28$ & $29.61 \pm 0.30$ & $8.95 \pm 0.08$ & $1.78 \pm 0.24$ & $0.27 \pm 0.01$ & $0.119 \pm 0.003$ & $0.06 \pm 0.01$ & $0.026 \pm 0.002$ \\
4 & $44.94 \pm 3.25$ & $28.38 \pm 4.37$ & $8.80 \pm 0.39$ & $1.90 \pm 0.16$ & $0.28 \pm 0.04$ & $0.117 \pm 0.004$ & $0.07 \pm 0.02$ & $0.019 \pm 0.007$ \\
5 & $46.16 \pm 1.05$ & $26.54 \pm 0.55$ & $7.92 \pm 0.22$ & $1.69 \pm 0.15$ & $0.26 \pm 0.01$ & $0.099 \pm 0.006$ & $0.06 \pm 0.01$ & $0.021 \pm 0.001$ \\
6 & $46.08 \pm 2.81$ & $24.08 \pm 2.25$ & $6.57 \pm 0.24$ & $5.00 \pm 0.26$ & $0.24 \pm 0.02$ & $0.073 \pm 0.002$ & $0.21 \pm 0.01$ & $0.054 \pm 0.005$ \\
7 & $47.54 \pm 1.69$ & $25.18 \pm 0.87$ & $6.72 \pm 0.07$ & $5.34 \pm 0.21$ & $0.23 \pm 0.01$ & $0.064 \pm 0.03$ & $0.21 \pm 0.01$ & $0.058 \pm 0.006$ \\
8 & $47.04 \pm 0.51$ & $25.57 \pm 0.86$ & $6.26 \pm 0.11$ & $4.99 \pm 0.04$ & $0.21 \pm 0.01$ & $0.032 \pm 0.004$ & $0.19 \pm 0.01$ & $0.031 \pm 0.009$ \\
9 & $45.98 \pm 1.05$ & $17.53 \pm 0.94$ & $4.18 \pm 0.07$ & $2.98 \pm 0.19$ & $0.19 \pm 0.01$ & $0.035 \pm 0.002$ & $0.17 \pm 0.01$ & $0.021 \pm 0.001$ \\
\hline
\end{tabular}

Nomenclature: Y butanol: yield of butanol from glicerol; Y 1,3-PDO: yield of 1,3-PDO from glycerol; Qbutanol: butanol productivity; Q1,3-PDO: 1,3-PDO productivity.

a Experiments defined in Table 1.

butanol and 1,3-PDO yields of $0.23 \pm 0.01 \mathrm{~g} \mathrm{~g}^{-1}$ and $0.08 \mathrm{~g} \mathrm{~g}^{-1}$, respectively, which were statistically different $(p=0.03$ and $p=0.07)$ from the ones obtained in the control $\left(0.20 \pm 0.01 \mathrm{~g} \mathrm{~g}^{-1}\right.$ and $0.17 \pm 0.02 \mathrm{~g} \mathrm{~g}^{-1}$, respectively). Using $5 \mathrm{~g} \mathrm{l}^{-1}$ of $\mathrm{NH}_{4} \mathrm{Cl}$, an increase in the $\mathrm{FeSO}_{4}$ concentration to $11 \mathrm{mg} \mathrm{l}^{-1}$ (Experiment 3), further increased the butanol yield to $0.27 \pm 0.01 \mathrm{~g} \mathrm{~g}^{-1}$, while the 1,3-PDO yield decreased to $0.06 \pm 0.01 \mathrm{~g} \mathrm{~g}^{-1}$, being both values significantly different $(p=0.02$ and $p=0.04)$ from the ones obtained in Experiment 2. This condition led to the higher butanol productivity, corresponding to $0.119 \pm 0.003 \mathrm{~g} \mathrm{l}^{-1} \mathrm{~h}^{-1}$. The concentration of butanol and 1,3PDO reached $8.95 \pm 0.08 \mathrm{~g} \mathrm{l}^{-1}$ and $1.78 \pm 0.24 \mathrm{~g} \mathrm{l}^{-1}$, respectively. The glycerol consumption was not significantly affected $\left(29.61 \pm 0.30 \mathrm{~g} \mathrm{l}^{-1}\right)$.

The increase of the salts concentration (Experiment 4), as well as the supplementation of biotin and p-aminobenzoic acid (Experiment 5) did not promote any improvement in the consumption of glycerol or production of butanol. Also, from experiments 6 to 9, it is clear that changes in the $\mathrm{CaCO}_{3}$ concentration (buffer agent) negatively affected the $C$. pasteurianum metabolism by decreasing the consumption of glycerol, which is especially notorious when a concentration of $1.5 \mathrm{gl}^{-1}$ was used. These results confirm the importance of $\mathrm{pH}$ control in the fermentation of glycerol by C. pasteurianum.

The influence of the culture medium composition on the product distribution in the fermentation of glycerol by $C$. pasteurianum has been previously reported [8,30]. In particular, Moon et al. [30] reported that the concentration of the nitrogen source is an important variable and that a high concentration of $\left(\mathrm{NH}_{4}\right)_{2} \mathrm{SO}_{4}$ negatively affects 1,3-PDO, favouring the production of butanol, which is in agreement with the results herein obtained, although the nitrogen source used in this work was $\mathrm{NH}_{4} \mathrm{Cl}$.

Iron is part of at least four important proteins directly related with the electron flow in Clostridium spp. namely, piruvate-ferredoxin oxidoreductase (PFOR) [39], ferredoxin [40], hydrogenases I and II [41] and iron-containing alcohol dehydrogenases [42]. The results herein obtained are in agreement with the ones reported by Dabrock et al. [8] who found that iron limitation in the fermentation of glycerol by $C$. pasteurianum DSM 525 somehow inhibits butanol production, which they related to the presence of iron-containing alcohol dehydrogenases. In C. pasteurianum it is possible to identify three major electron sinks; 1,3-PDO, hydrogen and butanol/ ethanol. Thus, the results reported by those authors and the ones herein gathered suggest that an iron limitation leads to a low butanol dehydrogenase activity, forcing the cell to favour the production of $1,3-\mathrm{PDO}$ as a way to regenerate $\mathrm{NAD}^{+}$, probably accompanied with a high hydrogen production. Conversely, the presence of iron in sufficient amounts leads to the production of butanol and a lower production of hydrogen. It is worth to note that the production of butanol consumes twice the amount of reducing equivalents than the production of 1,3-PDO (Fig. 1). A more detailed study on the effect of nitrogen and iron on the production of butanol by C. pasteurianum, including hydrogen evolution measurements, should be conducted in order to validate these assumptions.

\section{Conclusions}

In this work, we found that high concentrations of biodieselderived crude glycerol favour the production of butanol over 1,3-PDO. Also, it was demonstrated that it is possible to modulate the outcome of the fermentation towards the production of butanol by supplementing the culture medium with sodium butyrate or by adjusting the concentration of key nutrients.

Significant differences in glycerol consumption and butanol production are reported in the literature and also in comparison with the results herein obtained, thus reflecting the complexity of the regulatory mechanisms present in this strain. These differences can be partially explained by the culture media composition, but undoubtedly other variables are also involved in the process. The results gathered in this work suggest that there are other factors besides butanol inhibition and nutrient limitation that affect glycerol consumption.

\section{Acknowledgements}

The authors acknowledge the financial support from the Strategic Project PEst-OE/EQB/LA0023/2013; the project ref. 
RECI/BBB-EBI/0179/2012 (project number FCOMP-01-0124FEDER-027462); and the PhD grant given to R. Gallardo (ref SFRH/BD/42900/2008) funded by Fundação para a Ciência e a Tecnologia. The authors thank the MIT-Portugal Program for the support given to R. Gallardo.

\section{R E F E R E N C E S}

[1] Yazdani SS, Gonzalez R. Anaerobic fermentation of glycerol: a path to economic viability for the biofuels industry. Curr Opin Biotechnol 2007;18(3):213-9.

[2] Barbirato F, Himmi EH, Conte T, Bories A. 1,3-Propanediol production by fermentation: an interesting way to valorize glycerin from the ester and ethanol industries. Ind Crop Prod 1998;7:281-9.

[3] Johnson DT, Taconi KA. The glycerin glut: options for the value-added conversion of crude glycerol resulting from biodiesel production. Environ Prog 2007;26:338-48.

[4] Oil Price Information Service (OPIS). Pricing, news and analysis for buying and supplying ethanol-blended fuel and biodiesel. Ethanol Biodiesel Inf Serv June 2, 2014;11(22). Available from: http://www.opisnet.com/images/ productsamples/EBISnewsletter-sample.pdf [accessed 24.06.14].

[5] Qureshi N, Blaschek HP. ABE production from corn: a recent economic evaluation. J Ind Microbiol Biotechnol 2001;27(5):292-7.

[6] Ahn JH, Sang BI, Um Y. Butanol production from thin stillage using Clostridium pasteurianum. Bioresour Technol 2011;102:4934-7.

[7] Biebl H. Fermentation of glycerol by Clostridium pasteurianum - batch and continuous culture studies. J Ind Microbiol Biotechnol 2001;27:18-26.

[8] Dabrock B, Bahl H, Gottschalk G. Parameters affecting solvent production by Clostridium pasteurianum. Appl Environ Microbiol 1992;58(4):1233-9.

[9] Heyndrickx M, De Vos P, Vancanneyt M, De Ley J. The fermentation of glycerol by Clostridium butyricum LMG 1212 t2 and 1213t1 and C. pasteurianum LMG 3285. Appl Microbiol Biotechnol 1991;34:637-42.

[10] Jensen TO, Kvist T, Mikkelsen MJ, Christensen PV, Westermann P. Fermentation of crude glycerol from biodiesel production by Clostridium pasteurianum. J Ind Microbiol Biotechnol 2012;39(5):709-17.

[11] Khanna S, Goyal A, Moholkar VS. Production of n-butanol from biodiesel derived crude glycerol using Clostridium pasteurianum immobilized on amberlite. Fuel 2011;112:557-61.

[12] Luers F, Seyfried M, Daniel R, Gottschalk G. Glycerol conversion to 1,3-propanediol by Clostridium pasteurianum: cloning and expression of the gene encoding 1,3-propanediol dehydrogenase. FEMS Microbiol Lett 1997;154:337-45.

[13] Malaviya A, Jang YS, Lee SY. Continuous butanol production with reduced byproducts formation from glycerol by a hyper producing mutant of clostridium pasteurianum. Appl Microbiol Biotechnol 2011;93(4):1485-94.

[14] Taconi KA, Venkataramanan KP, Johnson DT. Growth and solvent production by Clostridium pasteurianum ATCC 6013 utilizing biodiesel-derived crude glycerol as the sole carbon source. Environ Prog Sustain Energy 2009;28(1):100-10.

[15] Venkataramanan KP, Boatman JJ, Kurniawan Y, Taconi KA, Bothun GD, Scholz C. Impact of impurities in biodieselderived crude glycerol on the fermentation by Clostridium pasteurianum ATCC 6013. Appl Microbiol Biotechnol 2012;93(3):1325-35.
[16] Choi WJ. Glycerol-based biorefinery for fuels and chemicals. Recent Pat Biotechnol 2008;2:173-80.

[17] Chen CK, Blaschek HP. Acetate enhances solvent production and prevents degeneration in Clostridium beijerinckii BA101. Appl Microbiol Biotechnol 1999;52:170-3.

[18] Chen CK, Blaschek HP. Effect of acetate on molecular and physiological aspects of Clostridium beijerinckii NCIMB 8052. Solvent production and strain degeneration. Appl Environ Microbiol 1999;65(2):499-505.

[19] Holt RA, Stephens GM, Morris JG. Production of solvents by Clostridium acetobutylicum cultures maintained at neutral $\mathrm{pH}$. Appl Environ Microbiol 1984;48:1166-70.

[20] Lee SM, Cho MO, Park CH, Chung Y-C, Kim JH, Sang B-I, et al. Continuous butanol production using suspended and immobilized Clostridium beijerinckii NCIMB 8052 with supplementary butyrate. Energy Fuel 2008;22:3459-64.

[21] Harris J, Mulder R, Kell DB, Walter RP, Morris JG. Solvent production by Clostridium pasteurianum in media of high sugar content. Biotechnol Lett 1986;8(12):889-92.

[22] Datta R, Zeikus JG. Modulation of acetone-butanol-ethanol fermentation by carbon monoxide and organic acids. Appl Environ Microbiol 1985;49(3):522-9.

[23] Husemann MHW, Papoutsakis ET. Enzymes limiting butanol and acetone formation in continuous and batch cultures of Clostridium acetobutylicum. Appl Microbiol Biotechnol 1989;31:435-44.

[24] Cornillot E, Nair RV, Papoutsakis ET, Soucaille P. The genes for butanol and acetone formation in Clostridium acetobutylicum ATCC 824 reside on a large plasmid whose loss leads to degeneration of the strain. J Bacteriol 1997;179(17):5442-7.

[25] Jones DT, Woods DR. Acetone-butanol fermentation revisited. Microbiol Rev 1986;50(4):484-524.

[26] Kashket ER, Cao ZY. Clostridial strain degeneration. FEMS Microbiol Rev 1995;17:307-15.

[27] Hartmanis MGN, Ahlman H, Gatenbeck S. Stability of solvent formation in Clostridium acetobutylicum during repeated subculturing. Appl Microbiol Biotechnol 1986;23:369-71.

[28] Yusof SJHM, Takriff MS, Amir A, Kadhum H, Mohammad AW, Jahim J. The effect of initial butyric acid addition on ABE fermentation by C. Acetobutylicum NCIMB 619. J Appl Sci 2010;10(21):2709-12.

[29] Himmi EH, Bories A, Barbirato F. Nutrient requirements for glycerol conversion to 1,3- propanediol by Clostridium butyricum. Bioresour Technol 1999;67:123-8.

[30] Moon C, Lee CH, Sang BI, Um Y. Optimization of medium compositions favoring butanol and 1,3 propanediol production from glycerol by Clostridium pasteurianum. Bioresour Technol 2011;102(22):10561-8.

[31] Hermann M, Fayolle F, Marchal R, Podvin L, Sebald M, Vandecasteele JP. Isolation and characterization of butanolresistant mutants of Clostridium acetobutylicum. Appl Environ Microbiol 1985;50:1238-43.

[32] Desai RP, Harris LM, Welker NE, Papoutsakis ET. Metabolic flux analysis elucidates the importance of the acid-formation pathways in regulating solvent production by Clostridium acetobutylicum. Metab Eng 1999;1:206-13.

[33] Husemann MHW, Papoutsakis ET. Comparison between in vivo and in vitro enzyme activities in continuous and batch fermentations of Clostridium acetobutylicum. Appl Microbiol Biotechnol 1989;30:585-95.

[34] Wang Y, Li X, Blaschek HP. Effects of supplementary butyrate on butanol production and the metabolic switch in Clostridium beijerinckii NCIMB 8052: genome-wide transcriptional analysis with RNA-Seq. Biotechnol Biofuels 2013;6(1):138.

[35] Jang Y-S, Lee JY, Lee J, Park JH, Im JA, Eom M-H, et al. Enhanced butanol production obtained by reinforcing the 
direct butanol-forming route in Clostridium acetobutylicum. MBio 2012;3(5):1-9.

[36] Richter H, Qureshi N, Heger S, Dien B, Cotta MA, Angenent LT. Prolonged conversion of n-butyrate to $\mathrm{n}$ butanol with Clostridium saccharoperbutylacetonicum in a twostage continuous culture with in-situ product removal. Biotechnol Bioeng 2012;109(4):913-21.

[37] Ramey DE, inventor; Environmental Energy, Inc., assignee. Continuous, two stage, dual path anaerobic fermentation of butanol and other organic solvents using two different strains of bacteria. United States patent US 5753474 A. 1998 May 19.

[38] Angenent LT, Wrenn BA. Optimizing mixed-culture bioprocessing to convert wastes into bioenergy. In: Wall JD, Harwood CS, Demain A, editors. Bioenergy. Washington, D.C.: ASM Press; 2008. p. 179-94.
[39] Gheshlaghi R, Scharer JM, Moo-Young M, Chou CP. Metabolic pathways of clostridia for producing butanol. Biotechnol Adv 2009;27:764-81.

[40] Graves MC, Rabinowitz JC. Cloning and nucleotide sequence determination of the Clostridium pasteurianum ferredoxin gene. Proc Natl Acad Sci U S A 1985;82:1653-7.

[41] Adams MWW, Eccleston E, Howard JB. Iron-sulfur clusters of hydrogenase I and hydrogenase II of Clostridium pasteurianum. Proc Natl Acad Sci U S A 1989;86:4932-6.

[42] Rappert S, Song L, Sabra W, Wang W, Zeng AP. Draft genome sequence of type strain Clostridium pasteurianum DSM 525 (ATCC 6013), a promising producer of chemicals and fuels. Genome A 2013;1(1):1-2. 